\title{
Artificial neural network simulations and experimental results: Removal of trichlorophenol from water using Chromolaena odorata stem
}

\author{
Derrick S Dlamini ${ }^{1}$, Ajay K Mishra' and Bhekie B Mamba ${ }^{1 *}$ \\ 'Department of Applied Chemistry, University of Johannesburg, PO Box 17011, Doornfontein 2028, Johannesburg, Gauteng, South Africa
}

\section{ABSTRACT}

\begin{abstract}
A novel adsorbent for trichlorophenol (TCP) has been developed through the treatment of Chromolaena odorata (Odorata) with iodated table salt. Odorata is an abundant and problematic alien plant which we have found to be effective in removing TCP from aqueous solutions. Kinetic batch tests demonstrated that at pH 5,99\% of TCP could be removed from a solution given sufficient adsorbent loading rate and adsorption contact time with Odorata treated with table salt. Adsorption data were found to fit a 2-layer feed-forward artificial neural network (ANN) with 10 neurons using the LevenbergMarquardt (trainlm) algorithm. The ability of Odorata to extract TCP from water was tested using equilibrium, kinetic and thermodynamic studies. Thermodynamic studies showed that the adsorption of TCP by the new adsorbent is thermally feasible and is governed by a chemical adsorption mechanism. It was established that the experimental data fit the selected adsorption isotherms in the following order: Langmuir $>$ Freundlich $>$ Temkin $>$ Dubinin-Radushkevich (D-R). Kinetic modelling was done using intra-particle diffusion, liquid-film, pseudo-first order and pseudo-second order models. With the aid of the normalised standard deviation, the pseudo-second order was found to be the appropriate rate expression for the adsorption data. Liquid-film diffusion was the rate-determining stage of the adsorption process.
\end{abstract}

Keywords: Chromolaena odorata; TCP; adsorption; table salt; ANN

\section{INTRODUCTION}

The pollution of water by organic materials is inexorable. Trichlorophenol (TCP) is one of the problematic compounds that end up in water as a result of industrial and agricultural activities. The main pollution sources containing chlorinated phenols like TCP are the wastewaters from pesticide, paint, solvent, pharmaceutics, wood, paper and pulp industries as well as water-disinfecting process (Hameed et al., 2008). Removing TCP from water is crucial. TCP is highly toxic, carcinogenic, structurally stable and persistent in the environment (Hameed et al., 2008). According to Tan et al. (2009) the stable C-Cl bond and the position of chlorine atoms relative to the hydroxyl group are responsible for TCP's toxicity and persistence in the biological environment.

Unlike inorganic water pollutants (like heavy metals), the concentration of organic compounds like TCP in water can be reduced by photo-degradation. Another technique used for the removal of TCP from aqueous media is membrane filtration technology. The major disadvantages of the membrane processes are the costs, as membrane filtration processes use pressure and their lifetime is limited before fouling (Subramani et al., 2009; Hoek et al., 2011). In accordance with the abundant literature data (Pei et al., 2007; Fan et al., 2011; Puyol et al., 2011; Zaghouane-Boudiaf et al., 2011), adsorption is one of the most popular techniques for the uptake of TCP from water. In recent years, a lot of attention has focused on developing effective adsorbents which are able to remove the pollutants from

\footnotetext{
To whom all correspondence should be addressed.

푱 +27 11-559-6516; fax: +27 11-559-6425;

e-mail: bmamba@uj.ac.za

Received 22 November 2012; accepted in revised form 28 January 2014.
}

the contaminated wastewater at low cost. Cost is actually an important parameter for comparing the suitability of adsorbent materials. According to Ahmaruzzaman (2008), an adsorbent can be categorised as low-cost if it requires little processing and is abundant in nature.

Most of the adsorbents that have been developed can be loosely classified as either inorganic or agricultural. One inorganic adsorbent that has been widely studied is clay. For example, Dlamini et al. used organo-montmorillonite (2012a) and Bentonite (2012b; 2012c) as filler in polymeric composites aimed at removing lead ions from water. Motsa et al. (2011) and Mthombo et al. (2011) used clinoptilolite as a filler material in the preparation of composites which were used for the removal of heavy metals from water. Such adsorbents (polymeric composites) are ideal for easy recovery and are stable in the water environment especially if the polymer used as a support is hydrophobic. The downside with composite adsorbents is that a lot of the filler needs to be used, while lower adsorption efficiency is recorded compared to powder adsorbents. The agricultural products that have been used as adsorbents for heavy metals and organic pollutants are Acacia leucocephala bark (Kumar et al., 2012), rice husk (Mahvi et al., 2004), sawdust (Shukla et al., 2002) and $\mathrm{TiO}_{2}$ (Dutta et al., 2010), to mention but a few.

Agricultural adsorbents are also called biosorbents. These materials contain various organic compounds (lignin, cellulose and hemicellulose) with polyphenolic groups that might be useful for binding TCP through different mechanisms. Agricultural products have to undergo treatment before they can be used in water treatment to remove lignin-based colour materials. To this end, $\mathrm{NaOH}$ (Mthombo et al., (2011), $\mathrm{KCl}$ and $\mathrm{NaCl}$ have been commonly used for preparing biosorbents; however, for this study the iodated salt has been used. 
In the present study, we explored the potential application of Chromolaena odorata (forthwith referred to as Odorata) treated using iodated table salt as a biosorbent for TCP in water. To the best of our knowledge no study has previously been reported on the use of Odorata treated with table salt as an adsorbent for TCP, or even the application of Odorata as an adsorbent. Odorata is a problematic alien plant that affects agricultural activities. This study is important because the processing of Odorata is cheap and it is abundantly available especially in Southern Africa, a region under clean-water stress. The utilisation of table salt treated-Odorata could solve the problem of access to cheaper material for adsorption in water pollutant control systems in the rural areas, especially in Third World countries.

Solving complex problems is a challenge and one efficient way of finding a solution is applying the 'divide and conquer' principle. This principle requires that a complex system be decomposed into simpler elements in order to be able to understand it. Neural networks are one way to achieving this. There are many levels of abstraction when it comes to the subject of artificial neural networks (ANN) in relation to neuroscience; therefore there is no simple definition of ANN. An artificial neuron is a computational model inspired by the natural biological neurons in the brain. In the present study, a 2-layer ANN model using a feed-forward propagation algorithm for modelling TCP adsorption by Odorata was designed. An optimisation study to determine the optimal number of neurons and transfer functions was done. A computer-simulated model like ANN is necessary in developing an automated wastewater treatment plant to reduce the operating cost of the plant.

\section{MATERIALS AND METHODS}

\section{Materials}

Odorata stems were collected at a non-agricultural area, Matsapha, Swaziland. The plant was collected at a non-agricultural area to avoid the presence of toxic soluble leachate, which could possibly emanate from pesticides. Iodated table salt was purchased at a supermarket at Campus Square, Johannesburg, South Africa. Trichlorophenol (TCP), $\mathrm{NaOH}$ and $\mathrm{HCl}$ were procured from Sigma Aldrich, Johannesburg, South Africa.

\section{Adsorbent preparation}

Odorata stems were chopped into small pieces of about $2 \mathrm{~cm}$ and then left to dry in open air for 8 months. Bark was stripped off and the dry stems were powdered and sieved to $\leq 38 \mu \mathrm{m}$ particles using a laboratory test sieve with a pore size of $38 \mu \mathrm{m}$. Moisture was removed from the micro-particles by using an oven programmed to $100^{\circ} \mathrm{C}$ for $24 \mathrm{~h}$. The micro-particles were then soaked in a solution of $0.5 \mathrm{M}$ iodated table salt. The solution was changed 3 times in 3 days. After that, the material was rinsed with deionised water until the filtrate had a $\mathrm{pH}$ of 7 and then dried again in an oven at $100^{\circ} \mathrm{C}$ to remove water.

\section{Fourier transform infrared (FTIR) spectroscopy}

The functional properties were measured directly by Bruker Tensor 27 Fourier transform infrared (FTIR) spectrometer equipped with diamond/ZnSe universal germanium-attenuated total reflectance (ATR). 10 scans were collected per sample at a resolution of $4 \mathrm{~cm}^{-1}$.

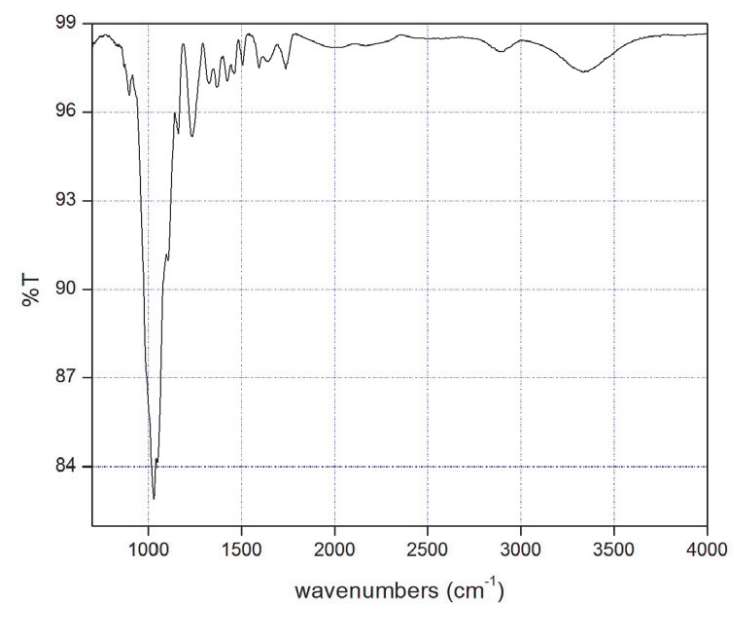

Figure 1

FT-IR spectrum of Odorata treated with iodated table salt

\section{Batch adsorption studies}

The adsorptive properties of the table salt treated-Odorata were tested for the removal of TCP from aqueous media. To minimise the losses of TCP by both photochemical decomposition and volatilisation, the experiments were carried out in brown bottles. The effect of $\mathrm{pH}$, contact time, temperature, and initial concentration was investigated using an adsorbent dose of $10 \mathrm{~g} \cdot \ell^{-1}$. The $\mathrm{pH}$ was adjusted by using $0.1 \mathrm{M} \mathrm{HCl}$ and $0.1 \mathrm{M} \mathrm{NaOH}$. The remaining concentration after adsorption was determined by UV spectroscopy (UV-2550, Shimadzu) at a wavelength $(\lambda)$ of $296 \mathrm{~nm}$. The pollutant uptake is reported in terms of per cent removal $(R(\%))$ :

$$
R(\%)=100 \times \frac{C_{o}-C_{t}}{C_{o}}
$$

where:

$C_{o}$ and $C_{t}$ are the initial concentration and the concentration at time $t$, respectively

\section{Definition of the ANN model}

In this study, the training, validation and testing of the ANN model was carried out using NN tool box ${ }^{\mathrm{TM}}$ on MATLAB 7.11.0 (R2010b) mathematical software. A two-layer feed-forward neural network using tansig and purelin transfer functions in the input and output layer, respectively, was employed to simulate the adsorption of TCP by the Odorata. The adsorption efficiency was used as the output.

\section{RESULTS AND DISCUSSION}

\section{FTIR analyses}

The FTIR results for the Odorata powder are shown in Fig. 1. Hypothetically, plant fibre materials contain chiefly cellulose and lignin. The spectra shows a weak broad peak at $3335 \mathrm{~cm}^{-1}$. This band can be assigned to free hydroxyl groups of cellulose (Szopa et al., 2009).

The band at $1738 \mathrm{~cm}^{-1}$ and $1424 \mathrm{~cm}^{-1}$ represents $-\mathrm{COOH}$ groups, probably from pectins, and $-\mathrm{CH}_{2}$ bending of cellulose, respectively (Alix et al., 2009). Another peak representing $\mathrm{COOH}$ occures at $1594 \mathrm{~cm}^{-1}$, suggesting the presence of lignin (Alix et al., 2009), as confirmed by the band at $667 \mathrm{~cm}^{-1}$. The 


\begin{tabular}{|l|c|c|c|c|c|}
\hline \multicolumn{5}{|c|}{ TABLE 1 } \\
Adapting algorithm \\
\hline \multicolumn{5}{|c|}{ Learning algorithm } \\
\hline & trainlm & trainbfg & trainoss & traincgb & traincgf \\
\hline $\boldsymbol{R}^{\mathbf{2}}$ & 1 & 0.9383 & 0.8889 & 9897 & 0.988 \\
\hline Train & 0.9998 & 0.9078 & 0.8997 & 0.9823 & 0.981 \\
\hline Validation & 0.9994 & 0.9183 & 0.8898 & 0.9906 & 0.9844 \\
\hline Test & 0.9994 & 0.9194 & 0.8591 & 0.9971 & 0.9881 \\
\hline Total & 0.9999 & & & \\
\hline MSE & 0.3087 & 11.25 & 22.1 & 2.433 & 4.087 \\
\hline Total & 0.13 &
\end{tabular}

broad and strong band at $1032 \mathrm{~cm}^{-1} \mathrm{can}$ be attributed to the C-O stretching vibration of the cellulose backbone (Alix et al., 2009). The oxygen atoms in the Odorata should play a big role in the adsorption of TCP from water. The $-\mathrm{COOH},-\mathrm{OH}$, and $\mathrm{C}-\mathrm{O}$ terminals should play a huge role in the removal of TCP from water.

\section{ANN design}

\section{Selection of training algorithm}

The learning algorithm is another parameter that deserves attention because different learning algorithms can produce a network with different accuracies towards specific data. The Levenberg-Marquardt (trainlm), Powell-Beale Restarts (traincgb), Fletcher-Reeves Update (traincgf), and QuasiNewton (trainbfg, trainoss) learning algorithms were tested through trial-and-error to discover the best performing algorithm for the data used in this study. The best algorithm was selected based on regression $\left(R^{2}\right)$ value and MSE. The results are summarised in Table 1.

A good training algorithm should have a high $R^{2}$ but a small MSE. The trainlm learning algorithm had the highest $R^{2}$ values, ranging from 0.9994 to 1.000 , and trainoss algorithm had the lowest values. These results clearly indicate that trainlm is the best training system for the data used in this study. Turana et al. (2011) found trainlm to be the optimum learning algorithm in modelling the biosorption of $\mathrm{Zn}$ (II) from leachate.

\section{Optimising network architecture}

The network design was optimised in terms of the number of neurons. The suitable number of neurons was selected based on the lowest MSE. The results of the effect of the number of neurons in the modelling of the adsorption of TCP by Odorata are illustrated in Fig. 2.

From Fig. 2, the MSE initially decreases with an increase in the number of neurons and increases thereafter. A parallel observation was reported by Yetilmezsoy et al. (2008) for a study modelling $\mathrm{Pb}(\mathrm{II})$ adsorption from aqueous environment by Antep pistachio shells. In the present study, the lowest MSE is 0.3489 , corresponding to 10 neurons. The increment at higher neuron numbers can be ascribed to the characteristics of the MSE performance index and the input vector used (Yetilmezsoy et al., 2008). Based on these results, 10 neurons in the hidden layer were considered optimal for the modelling of TCP adsorption by Odorata treated with table salt.

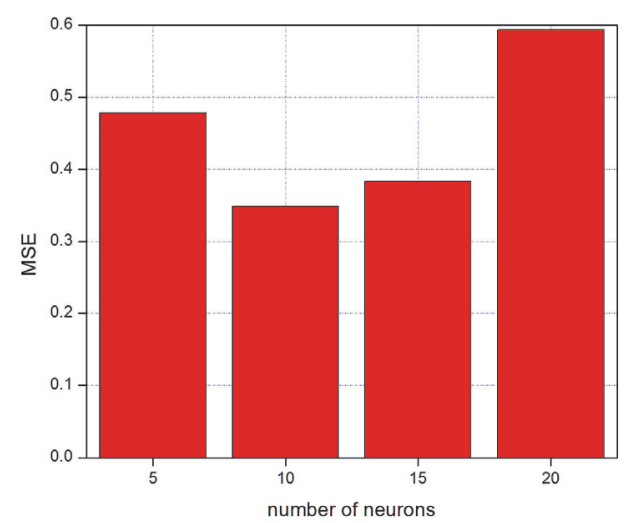

Figure 2

Effect of the number of neurons

\section{Trichlorophenol adsorption and ANN application}

\section{Effect of initial concentration and agitation time}

The results illustrating how the adsorption of TCP by the Odorata changed with time and initial concentration are shown in Fig. 3. The results are presented in terms of adsorption efficiency.

Based on these results, the plots can be divided into 3 stages. The first stage occurs in the initial $30 \mathrm{~min}$ of the experiment. In this stage, the adsorption happens faster because of the abundant available adsorption sites. In the second stage the amount of TCP adsorbed onto the Odorata is approaching a state of dynamic equilibrium with the amount of TCP desorbed from the Odorata. The adsorption time profile has a lower slope at this stage than in the first stage. The third stage can be distinguished by the constant adsorption efficiency as a result of saturation. The contact time of equilibrium was found to be 60 min, after which no more TCP was removed from solution. The 60 -min equilibrium contact time is interesting because equilibrium time is one of the important parameters for economical wastewater treatment applications (Denizli et al., 2005). Denizli et al. (2005) reported an equilibrium time of $240 \mathrm{~min}$ in a study using dead fungus Pleurotus sajor caju as an adsorbent for TCP. Zaghouane-Boudiaf et al. (2011) investigated the adsorption of TCP using organo-montmorillonite and reported an equilibrium contact time of $30 \mathrm{~min}$.

The initial concentration of TCP was varied from 50 to $100 \mathrm{mg} \cdot \ell^{-1}$. At an initial concentration of $50 \mathrm{mg} \cdot \ell^{-1}$, the equilibrium adsorption efficiency was found to be $99 \%$. When the concentration was increased to $65 \mathrm{mg} \cdot \ell^{-1}$, the equilibrium adsorption efficiency slightly decreased to $94 \%$. In the initial concentration range used here, the lowest per cent adsorption $(88 \%)$ was recorded at an initial concentration of 100 $\mathrm{mg} \cdot \ell^{-1}$. These adsorption efficiencies suggest that the Odorata could be useful in TCP removal from water. The fibre derives adsorption properties from its capability for hydrogen bonding, Van der Waals' interactions or hydrophobic bonding arising from either strong or weak interactions. Plant material generally possesses crystalline and amorphous regions in the cellulose structure. The amorphous region can absorb dyes easily. The hydrophilic hydroxyl groups present in the amorphous region can chemically interact with suitable functional groups of the target pollutant. However, the crystalline region is impermeable and this character can be eliminated by chemical modification. 


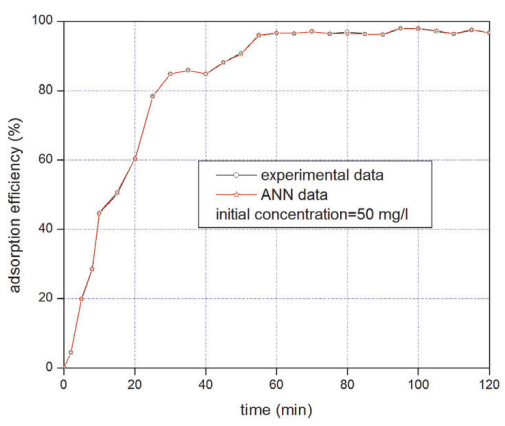

(a)

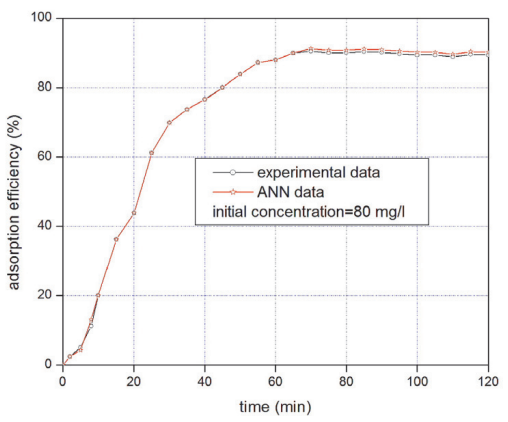

(c)

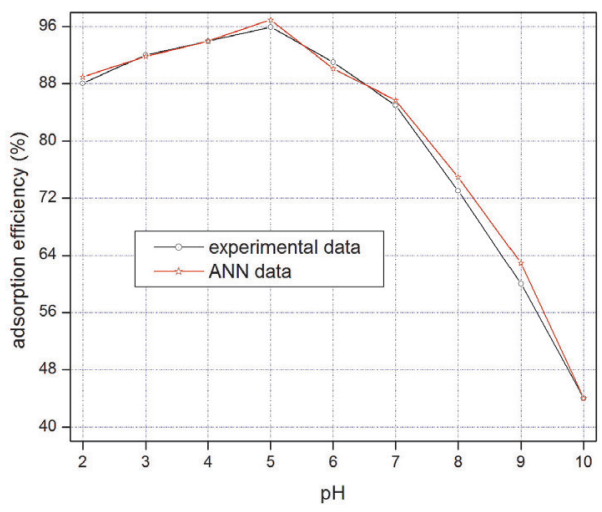

Figure 4

Effect of $\mathrm{pH}$ on the adsorption of TCP

The time profile for each initial concentration was simulated using the 2-layer feed-forward ANN. It can be seen in Fig. 3 that the simulated adsorption efficiency was generally close to the experimental per cent TCP adsorption. The standard deviation was calculated using the real adsorption and simulated data and was plotted against time (see Appendix: Fig. S1). The standard deviation ranged from 0 to 1.5 with more data densely clustered below 0.25 , indicating that there is indeed a close correlation between the experimental and ANN data.

\section{Effect of $\mathrm{pH}$ on the adsorption efficiency}

Solution $\mathrm{pH}$ is one of the most fundamental parameters for adsorption because it determines the interaction in the wateradsorbent interface. The effect of $\mathrm{pH}$ on the adsorption of TCP onto Odorata is shown in Fig. 4 in terms of per cent adsorption.

From Fig. 4, the adsorption initially increased gradually with an increase in $\mathrm{pH}$ until $\mathrm{pH} 5$, and then decreased aggressively thereafter with an increase in $\mathrm{pH}$. Hydrogen bonding

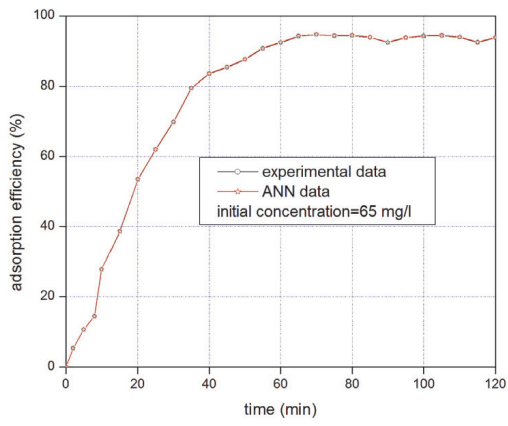

(b)

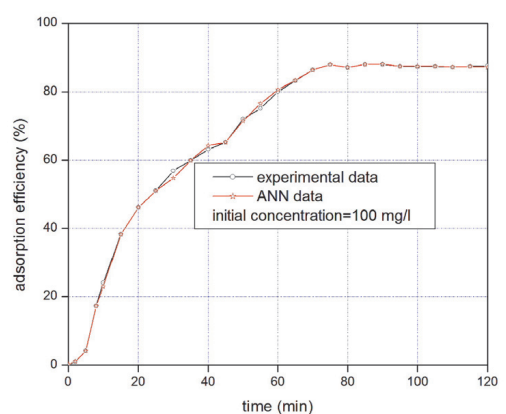

(d)
Figure 3

Effect of initial concentration at $\mathrm{pH} 5$

of the phenolic hydroxyl and chloride groups in TCP with the oxygen sites on the surface of Odorata is the most likely mechanism for adsorption. The adsorption may not be exclusively due to the phenolic hydroxyl and chloride groups; physical adsorption is also possible. At lower $\mathrm{pH}$ there would be hydronium ions on the surface of the adsorbent and the TCP would be positively charged due to hydration. The charges on the TCP and Odorata would cause repulsion between the two species; hence the observed trend between $\mathrm{pH} 2$ and 5 . As the $\mathrm{pH}$ of the solution increases, there would be a decrease in the hydronium ions and the concentration of hydroxide ions would be augmented. At higher pH, TCP is partially ionised (Fan et al., 2011) while the functional groups of Odorata are either neutral or negatively charged (Kumar et al., 2012). Therefore, the decrease in the adsorption efficiency above $\mathrm{pH} 5$ can be attributed to repulsions between the TCP and the Odorata. Moreover, the partially ionised TCP is highly soluble in water and forms strong phenolate-water bonds thereby 'blocking' the adsorbate from interacting with the adsorbent. A similar trend in the change of TCP adsorption as a function of $\mathrm{pH}$ was reported by Kumar et al. (2012) in the uptake of 2,4,6-trichlorophenol from aqueous solutions by Acacia leucocephala bark. Based on the results in Fig. $4, \mathrm{pH} 5$ is the optimum $\mathrm{pH}$ for the removal of TCP from water by Odorata. Thus, the adsorption of TCP can be controlled by changing the $\mathrm{pH}$. It is worth noting that the $\mathrm{NN}$ data curve is identical to the experimental data curve.

\section{Effect of temperature on the adsorption efficiency}

The effect of temperature on the removal of TCP from water using Odorata was investigated at a temperature range of 293-323 K. The results are shown in Fig. 5. The adsorption efficiency increased with an increase in temperature. Tan et al. (2009) reported a similar observation in a study on the removal of 2,4,6-trichlorophenol from water using oil palm empty fruit bunch based activated carbon at a temperature range of 303-323 K. 


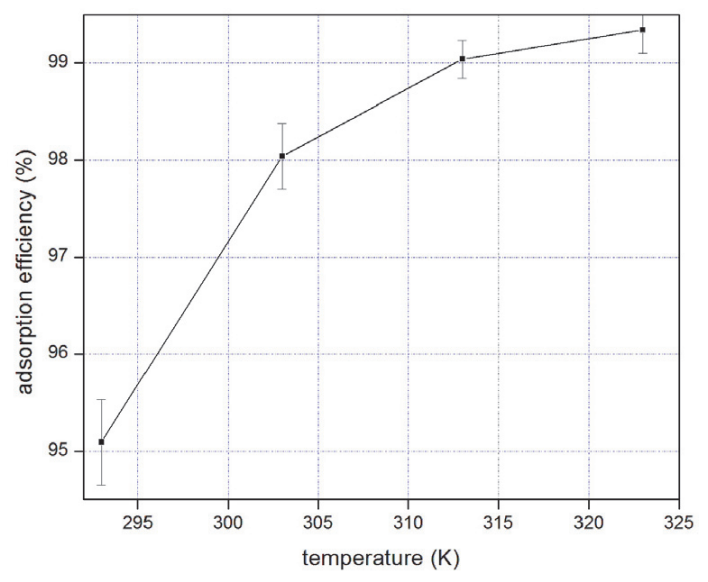

Figure 5

Effect of temperature on the adsorption of TCP at $\mathrm{pH} 5$

The observed increase in TCP removal from water by the Odorata can be attributed to an increase in the TCP mobility with an increase in temperature. To gain deeper insight into the effect of temperature on the uptake of TCP by the Odorata the thermodynamic feasibility of the study was determined using the thermodynamic parameters: free Gibbs energy $\left(\Delta G^{0}\right)$, enthalpy $\left(\Delta H^{0}\right)$, and entropy $\left(\Delta S^{0}\right) . \Delta G^{0}$ was computed using the following relation:

$$
\Delta G^{0}=-R T \ln K_{C}
$$

where:

$R$ is the gas constant $\left(8.314 \mathrm{~J} \cdot \mathrm{mol}^{-1} \cdot \mathrm{K}^{-1}\right)$

$T$ is temperature $(\mathrm{K})$

$K_{\mathrm{c}}$ is the apparent equilibrium constant $\left(K_{\mathrm{c}}\right)$ of the adsorption and is defined in terms of the TCP adsorbed at equilibrium $\left(C_{a d s}\right)$ and the equilibrium TCP concentration $\left(C_{e}\right)$, as per the following equation (Sölener et al., 2008):

$$
K_{c}=\frac{C_{a d s}}{C_{e}}
$$

The values of $\Delta H^{0}$ and $\Delta S^{0}$ were calculated from the slope and intercept of the plot of $\ln K_{c} v s$. reciprocal of temperature $(T)$ (Sölener et al., 2008; Tan et al., 2009). $K_{c}$ is related to $\Delta H^{0}$ and $\Delta S^{0}$ by the following equation:

$$
\ln K_{c}=\frac{\Delta S^{0}}{R}-\frac{\Delta H^{0}}{R T}
$$

Equation (4) assumes that there is a linear relationship between the $\ln K$ and $1 / T$. The thermodynamic parameters tabulated using this equation are given in Table 2.

It has been reported that negative values of $\Delta G^{0}$ indicate

\begin{tabular}{|c|c|c|c|c|}
\hline & Thern & $\begin{array}{l}\text { TABLE } 2 \\
\text { namic } p\end{array}$ & neters & \\
\hline$\Delta \mathrm{G}^{\circ}(\mathrm{kJ} \cdot \mathrm{mo}$ & & & & \\
\hline & nperature & & $\begin{array}{c}\Delta \mathrm{H}^{\circ} \\
\left(\mathrm{kJ} \cdot \mathrm{mol}^{-1}\right)\end{array}$ & $\begin{array}{c}\Delta \mathrm{S}^{\circ} \\
\left(\mathrm{J} \cdot \mathrm{mol}^{-1} \cdot \mathrm{K}\right)\end{array}$ \\
\hline 293 & 303 & 313 & & \\
\hline-84.09 & -107.3 & -123.1 & -63.8 & -242.6 \\
\hline
\end{tabular}
spontaneous adsorption while positive values mean that the adsorption process is non-spontaneous (Shin et al., 2010; Sen et al., 2011). Errais et al. (2011) reported that the negative values of $\Delta G^{0}$ indicate that the adsorption process is thermodynamically feasible. Therefore, the adsorption of TCP on Odorata is thermodynamically feasible at the temperature range used in this study. According to Zaghouane-Boudiaf et al. (2011), $\Delta G^{0}$ values ranging from 0 to $-30 \mathrm{~kJ} \cdot \mathrm{mol}^{-1}$ and -80 to $-400 \mathrm{~kJ} \cdot \mathrm{mol}^{-1}$ indicate physical and chemical adsorption, respectively. The values of $\Delta G^{0}$ in Table 2 show that the adsorption of TCP by Odorata occurred through chemical adsorption. This observation was supported by the $\Delta H^{0}$ which falls within the range: -42 to $-125 \mathrm{~kJ} \cdot \mathrm{mol}^{-1}$.

\section{Adsorption isotherms}

In an attempt to optimise the design of an adsorption system, it is imperative to find the most appropriate correlation for the equilibrium curves (Hameed et al., 2008). Equilibrium results are reported in terms of the amount of TCP adsorbed at equilibrium per unit weight of the adsorbent, $q_{\mathrm{e}}\left(\mathrm{mg}_{\mathrm{g}} \mathrm{g}^{-1}\right)$, which can be represented as follows:

$$
q_{e}=\frac{\left(C_{o}-C_{e}\right) v}{w_{s}}
$$

where:

$v$ is the analyte solution volume $(\ell)$

$w_{s}$ is the weight of the adsorbent $(\mathrm{g})$

Herein, 4 adsorption isotherms: the Langmuir, Freundlich, Dubinin-Radushkevich (D-R) and Temkin were employed to fit the adsorption data of TCP adsorption from water by Odorata. The Langmuir isotherm assumes monolayer adsorption and is expressed as follows:

$$
\frac{C_{e}}{q_{e}}=\frac{1}{b Q_{0}}+\frac{C_{e}}{Q_{0}}
$$

where:

$Q_{0}$ is the adsorption capacity $\left(\mathrm{mg} \cdot \mathrm{g}^{-1}\right)$

$b$ is the energy of adsorption $\left(\ell \cdot \mathrm{mg}^{-1}\right)$

If the data fit a Langmuir isotherm, a plot of $C_{\mathrm{e}} / q_{\mathrm{e}}$ versus $C_{e}$ should give a linear plot (results shown in Fig. 6(a)). The essential feature of the Langmuir isotherm is the equilibrium parameter, $R_{L}$, a dimensionless constant that can be presented as follows:

$$
R_{L}=\frac{1}{1+b C_{o}}
$$

$R_{L}$ indicates whether the adsorption is unfavourable $\left(R_{\mathrm{L}}>1\right)$, linear $\left(R_{\mathrm{L}}=1\right)$, favourable $\left(0<R_{\mathrm{L}}<1\right)$ or irreversible $\left(R_{\mathrm{L}}=0\right)$ (Sölener et al., 2008). Therefore, the adsorption of TCP onto the Odorata was favourable under conditions used in this study. The Freundlich model is used to describe heterogeneous systems. The isotherm assumes that the adsorbent surface sites have an array of different binding energies. The Freundlich isotherm is presented as follows:

$$
\log q_{e}=\log K_{F}+\frac{1}{n} \log C_{e}
$$

where:

$q_{\mathrm{e}}$ is the amount adsorbed at equilibrium $\left(\mathrm{mg} \cdot \mathrm{g}^{-1}\right)$

$C_{e}$ is the equilibrium concentration of the adsorbate

$K_{\mathrm{F}}$ and $n$ are the Freundlich constants which can be determined from the linear graph of $\log q_{e}$ against $\log C_{e}$. The Freundlich graph is shown in Fig. 6(b). 


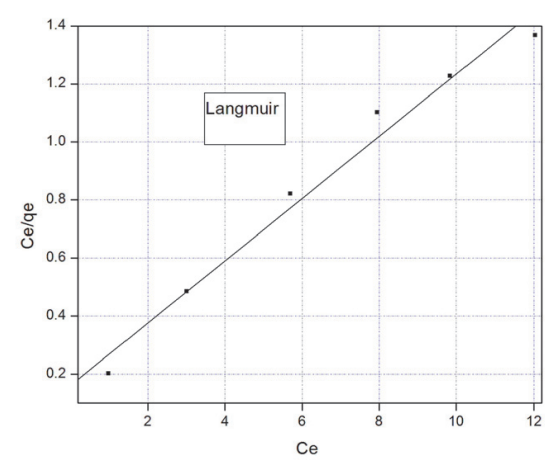

(a)

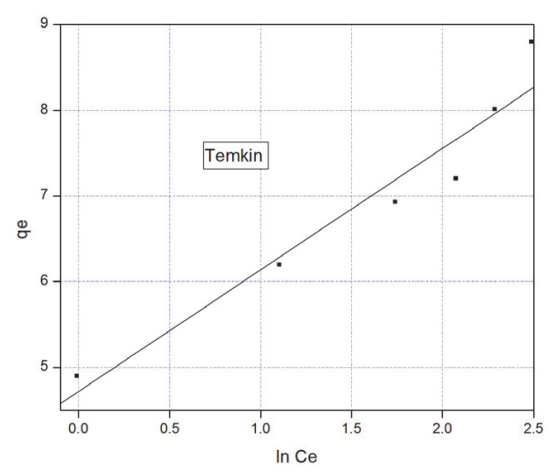

(c)

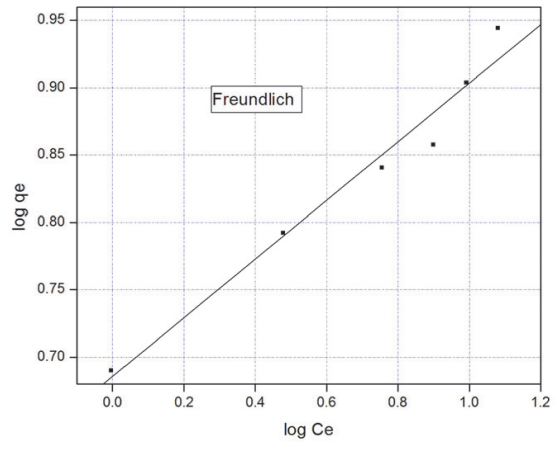

(b)

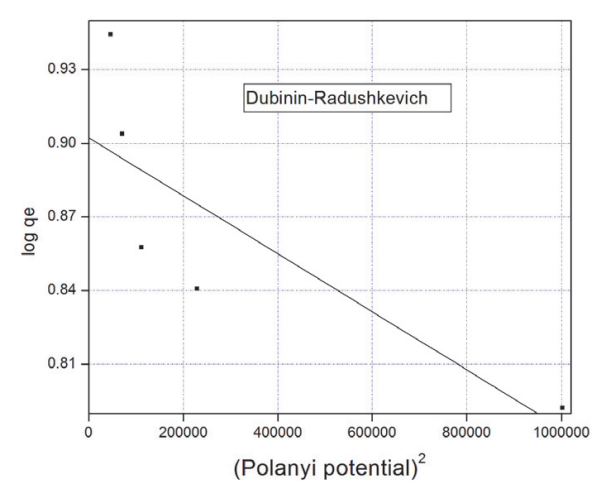

(d)
Figure 6

Adsorption isotherms: (a) Langmuir; (b) Freundlich; (c) Temkin, and; (d) DubininRadushkevich isotherms
Another isotherm that was used in the present work is the Temkin model. The linear form of the Temkin isotherm is expressed as follows (Kumar et al., 2012):

$$
\varepsilon=R T \ln \left[1+\frac{1}{C_{e}}\right]
$$

where:

$R T / b_{T}=B\left(\mathrm{~J} \cdot \mathrm{mol}^{-1}\right)$ is the Temkin constant related to heat of sorption

$A\left(\ell \cdot \mathrm{g}^{-1}\right)$ is the equilibrium binding constant corresponding to the maximum binding energy.

The TCP adsorption data was fitted in the Temkin model by plotting $q e$ vs. $\ln C_{e}$ and the results are shown in Fig. 6(c). The D-R model is shown below (Dlamini et al., 2012a):

$$
\ln q_{e}=\ln q_{m}-K \varepsilon^{2}
$$

where:

$q_{m}$ is the theoretical saturation capacity

$\varepsilon$ is the Polanyi potential calculated as follows:

$$
q_{e}=\frac{R T}{b_{T}} \ln A+\frac{R T}{b_{T}} \ln C_{e}
$$

A linear plot of $\ln q_{e}$ against $\varepsilon^{2}$ is accepted as an indication that the data fits the D-R model. The D-R curve is shown in Fig. 6(d).

According to Kara et al. (2008), the constant, $K$, is related to the mean free energy of sorption per mole of the sorbate as it is transferred to the surface of the solid from infinite distance in the solution, and this energy can be computed using the following relationship:

$E=(2 K)^{-1 / 2}$

\begin{tabular}{|l|c|c|c|}
\hline \multicolumn{4}{|c|}{ TABLE 3 } \\
\hline \multicolumn{1}{|c|}{ Adsorption isotherm parameters } \\
\hline \multirow{2}{*}{ Langmuir } & $Q_{o}$ Constants & $\boldsymbol{R}^{2}$ \\
\hline \multirow{2}{*}{ Freundlich } & 9.311 & 1.493 & 0.9787 \\
\hline & $K_{F}$ & $1 / n$ & 0.9687 \\
\hline \multirow{2}{*}{ Tempkin } & 1.985 & 0.2175 & \\
\hline \multirow{2}{*}{ D-R } & $A_{T}$ & $\mathrm{~b}_{\mathrm{T}}$ & 0.9338 \\
\cline { 2 - 4 } & 1.351 & 1709 & \\
\cline { 2 - 4 } & $q_{m}$ & $E$ & 0.6635 \\
\cline { 2 - 4 } & 2.654 & 0.4861 & \\
\hline
\end{tabular}

The parameters tabulated from the 4 isotherms are summarised in Table 3. The correlation coefficients $\left(R^{2}\right)$ suggest that the experimental data fit the models in the following order: Langmuir $>$ Freundlich $>$ Temkin $>$ D-R. The Langmuir, Freundlich and Temkin models gave good $R^{2}(>0.900)$.

A value of $1 / n$ between 0 and 1 is a measure of surface heterogeneity, becoming more heterogeneous as its value approaches zero (Kumar et al., 2012). From the value of $1 / n$ shown in Table 3 , the adsorption of TCP onto Odorata is favourable and occurred in a heterogeneous surface. Heterogeneity in plant fibre adsorbents for molecules like TCP arise from the different atoms $(\mathrm{H}$ and $\mathrm{O}$ ) participating in the adsorption process. The low energy $(0.4861 \mathrm{~kJ} / \mathrm{mol})$ calculated obtained from the D-R model confirms that the removal of TCP was indeed mostly though dipole-dipole physical adsorption in conjunction with electrostatic adsorption.

\section{ADSORPTION KINETICS}

Adsorption occurs in at least 4 stages that can have different 


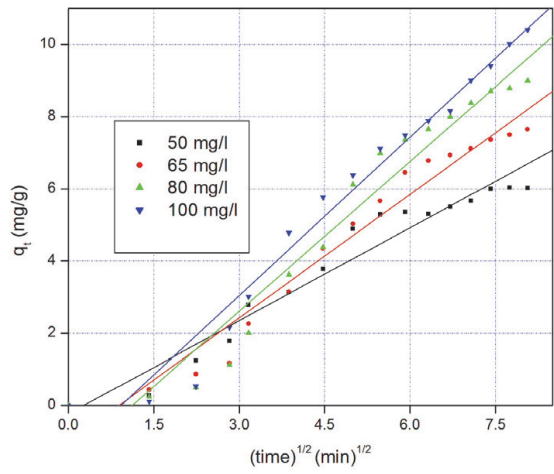

(a)

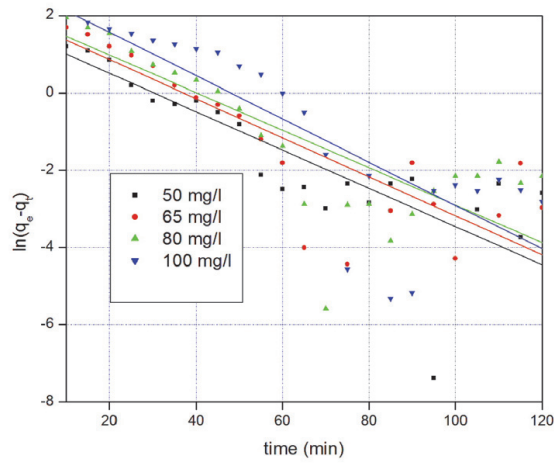

(c)

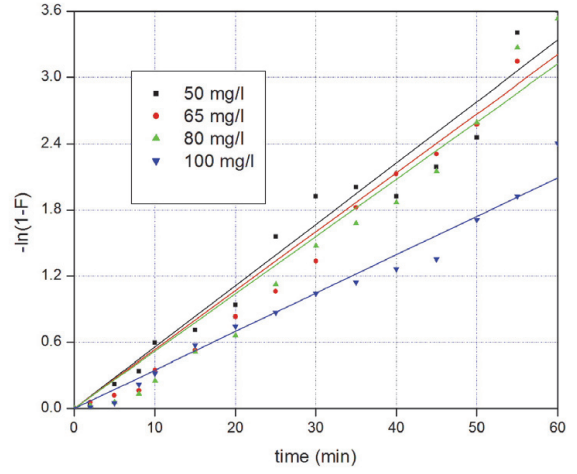

(b)

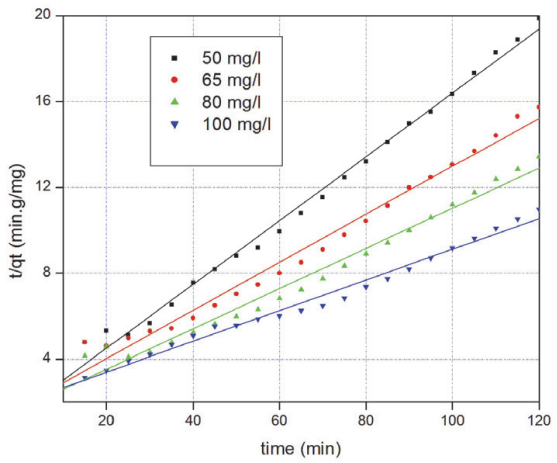

(d)
Figure 7

Kinetic models: (a) pseudo-first order; (b) pseudosecond order; (c) intra-particle diffusion, and (d) liquid-film model. kinetic rates (Bystrzejewski et al., 2011). Firstly, the transport of the analyte will involve the migration of TCP from the bulk liquid to the adsorbent particles. Since the Odorata particles would be enveloped by liquid film, the second stage of the adsorption process of TCP involves penetration through the film to gain contact with the adsorbent particles. In the next step, there will be intra-particle diffusion of the TCP into the Odorata particles and then adsorption will occur. It is imperative to identify the dominant (slowest) stage because it may control the kinetics of the adsorption process and therefore determine the removal rate of TCP from the aqueous solution.

However, since the adsorption experiments were done under vigorous shaking $\left(250 \mathrm{r} \cdot \mathrm{min}^{-1}\right)$, the migration of the TCP from the liquid phase to the surface of the Odorata particles cannot be the rate-determining step. The experiments were done at $\mathrm{pH} 5$, an optimum $\mathrm{pH}$ for the adsorption of TCP by Odorata, so it could be assumed that the interaction between the adsorbent and adsorbate occurred instantly. In that regard, the interaction (binding) of TCP with the Odorata may not be the rate-limiting stage. Therefore, the rate-determining step could either be the migration of TCP through the Odorata particle pores (intra-particle diffusion) or the liquid-film diffusion process. According to Alemayehua et al. (2011) the following equation, which is known as the liquid-film model, can be applied to predict whether liquid-film diffusion is the rate-determining step in an adsorption process:

$$
\operatorname{Ln}(1-F)=-k_{f d} t
$$

where:

$F$ is a constant $\left(F=q_{\mathrm{t}} / q_{\mathrm{e}}\right)$

$k_{f d}$ is the adsorption rate constant

$t$ is time in $\mathrm{min}$

$$
q_{t}=\frac{\left(C_{o}-C_{t}\right) v}{w_{s}}
$$

where:

$C_{\mathrm{o}}$ and $C_{t}$ represent the initial concentration and the remaining concentration at different time intervals.

A linear plot of $-\ln (1-F)$ against $t$, passing through the origin $(0,0)$, indicates that liquid film diffusion is the rate-determining step of the kinetics of the adsorption process. According to Li et al. (2011) and Wang et al. (2011) the following equation can be applied to predict whether intra-particle diffusion if the rate-limiting step in an adsorption process:

$$
q_{t}=K_{p} t^{1 / 2}+C
$$

where:

$$
\begin{aligned}
& K_{\mathrm{p}} \text { is the intra-particle diffusion rate constant, in } \\
& \mathrm{mg} \cdot \mathrm{g}^{-1} \cdot \mathrm{min}^{1 / 2}
\end{aligned}
$$

When the plot $q_{\mathrm{t}}$ against $t^{1 / 2}$ is linear and passes through the origin $(0,0)$ then the intra-particle diffusion process is the primary limiting mechanism (Tofighy et al., 2011). Figure 7(a) and Figure 7(b) illustrate the results for liquid-film diffusion and intra-particle diffusion transport models, respectively. Intra-particle diffusion was possible because once the TCP molecules are saturated at the exterior surface of Odorata, the TCP molecules can enter the pores of the adsorbent and adsorb on the interior surface of the particles (Hameed et al., 2008). Comparing the results in Figs 7(a) and 7(b), it can be seen that the liquid-film was the rate-determining step. This observation could be due to the hydrophilic nature of the Odorata (like most plant materials). Hydrophilic materials tend to interact with water strongly through hydrogen bonding thereby 
decelerating the water permeability and this will slow down the rate at which the TCP reaches the adsorbent active sites. In order to check the applicability of rate law, kinetic data were fitted to the pseudo-first order equation and pseudo-second order rate expressions. Investigating kinetics of adsorption experiments is important especially if the experiments are to be scaled up. The pseudo-first order equation is expressed as follows:

$$
\ln \left(q_{e}-q_{t}\right)=\ln \left(q_{e}\right)-\frac{k_{1}}{2.303} t
$$

where:

$q_{\mathrm{e}}$ and $q_{\mathrm{t}}$ refer to the amount of TCP $\left(\mathrm{mg} \cdot \mathrm{\ell}^{-1}\right)$ adsorbed on the Odorata at equilibrium

$t$ is time ( $\mathrm{min}$ )

$k_{1}$ is the rate constant $\left(\mathrm{min}^{-1}\right)$

Plotting $\ln \left(q_{\mathrm{e}}-q_{\mathrm{t}}\right)$ vs. $t$ should yield a linear graph (shown in Fig. 7(c)) where the experimental equilibrium adsorption capacity $q_{\mathrm{e} \text { exp }}$ is extrapolated from the y-intercept. The pseudosecond order reaction kinetic model is expressed by the following relation (Doulia et al., 2009):

$$
\frac{t}{q_{t}}=\frac{1}{k_{2} q_{e}^{2}}+\frac{t}{q_{e}}
$$

where:

$k_{2}$ is the second-order rate constant

If second-order kinetics is applicable, $t / q_{\mathrm{t}}$ should show a linear relationship with $t$. The results are shown in Fig. 7(d).

The $R^{2}$ corresponding to the pseudo-first order equation was found to be: $0.6638\left(50 \mathrm{mg} \cdot \ell^{-1}\right), 0.6565\left(65 \mathrm{mg} \cdot \ell^{-1}\right), 0.7113$ (80 mg. $\left.\ell^{-1}\right)$, and $0.7622\left(100 \mathrm{mg} \cdot \ell^{-1}\right)$. The pseudo-second order model had the following $R^{2}: 0.9932\left(50 \mathrm{mg} \cdot \ell^{-1}\right), 0.9827$ (65 $\left.\mathrm{mg} \cdot \ell^{-1}\right), 0.9775\left(80 \mathrm{mg} \cdot \ell^{-1}\right)$, and $0.9860\left(100 \mathrm{mg} \cdot \ell^{-1}\right)$. Based on the $R^{2}$ values, the adsorption of TCP onto Odorata follows the pseudo-second order model. This observation was confirmed by the normalised standard deviation, $\Delta q(\%)$, which can be expressed as follows:

$$
\Delta q(\%)=100 \sqrt{\frac{\sum\left[\left(q_{e, \exp }-q_{e, c a l}\right) / q_{e, \exp }\right]^{2}}{N-1}}
$$

where:

$q_{\mathrm{e}, \exp }$ and $q_{\mathrm{e}, \mathrm{cal}}$ is the experimental and calculated saturation adsorption amount, respectively

$N-1$ is the degrees of freedom

The experimental $q_{e}$ and the calculated $q_{e}$ are summarised in Table 4.

The $\Delta q(\%)$ obtained for the pseudo-first order kinetic model ranged from $22.02 \%$ to $33.21 \%$ for TCP initial concentration range used in this study. The $\Delta q(\%)$ for the pseudo-first order

TABLE 4

Adsorption capacity tabulated from kinetic models

\begin{tabular}{|l|c|c|c|c|c|}
\hline \multirow{2}{*}{$\begin{array}{l}\mathrm{C}_{\mathrm{o}} \\
(\mathrm{mg} / \mathrm{\ell})\end{array}$} & $\mathrm{q}_{\mathrm{e}, \text { exp }}$ & \multicolumn{2}{|c|}{ pseudo-first order } & \multicolumn{2}{c|}{ pseudo-second order } \\
\cline { 3 - 6 } & & $\mathrm{q}_{\mathrm{e}, \text { al }}$ & $\Delta q(\%)$ & $\mathbf{q}_{\mathrm{e}, \text { cal }}$ & $\Delta q(\%)$ \\
\hline 100 & 11.23 & 14.7 & 30.9 & 14 & 24.67 \\
\hline 80 & 9.046 & 7.033 & 22.25 & 10.67 & 17.95 \\
\hline 65 & 7.656 & 5.97 & 22.02 & 8.928 & 16.61 \\
\hline 50 & 6.113 & 4.083 & 33.21 & 6.729 & 10.08 \\
\hline
\end{tabular}

was relatively higher compared to the $\Delta q(\%)$ values obtained for the pseudo-second order model. The $\Delta q(\%)$ corresponding to the pseudo-first order kinetic model ranged from $10.08 \%$ to $24.67 \%$. These results confirm that the adsorption of TCP by the table salt treated-Odorata can be described by the pseudosecond order model.

\section{CONCLUSIONS}

This work has shown that the table salt treated-Odorata has potential as an adsorbent for TCP. It has been demonstrated that ANN could be used to simulate the removal of TCP from aqueous media using the table salt treated-Odorata. The following conclusions are drawn from the results of the present work:

- Kinetic batch tests demonstrated that at $\mathrm{pH} 5,99 \%$ of TCP could be removed from solution given sufficient loading rate and contact time using Odorata treated with table salt.

- Thermodynamic studies showed that the adsorption of TCP by the new adsorbent is thermally feasibly and is governed by chemical adsorption mechanism.

- It was established that the experimental data fit the selected adsorption isotherms in the following order: Langmuir $>$ Freundlich $>$ Temkin $>$ D-R.

- Kinetic modelling of removal of phenol was done using the pseudo-first order and pseudo-second order rate expressions. Based on the normalised standard deviation, the pseudo-second order is suitable to describe the adsorption of TCP by Odorata. Further kinetic modelling revealed that liquid-film diffusion is the rate-determining step in the adsorption process.

The advantages of using a plant material in water treatment are low moisture resistance which allows swelling of the fibres, low heat resistance which makes thermal recycling possible, environmentally friendly and easy processing (no wearing of tools and no skin irritation), and low production and investment costs.

\section{ACKNOWLEDGEMENTS}

This work was financially supported by the University of Johannesburg through the Faculty of Science. The authors would like to extend their sincere gratitude to Mr. Thembinkosi Cower Simelane for collecting the Chromolaena odorata stems.

\section{REFERENCES}

AHMARUZZAMAN M (2008) Adsorption of phenolic compounds on low-cost adsorbents: A review. Adv. Coll. Interf. Sci. 14 48-67.

ALEMAYEHUA E, THIELE-BRUHN S and LENNARTZA B (2011) Adsorption behaviour of $\mathrm{Cr}(\mathrm{VI})$ onto macro- and micro-vesicular volcanic rocks from water. Sep. Purif. Technol. 78 55-61.

ALIX A, PHILIPPE E, BESSADOK A, LEBRUN L, MORVAN C and MARAIS S (2009) Effect of chemical treatments on water sorption and mechanical properties of flax fibres. Bioresour. Technol. 100 4742-4749.

BYSTRZEJEWSKI M and PYRZYŃSKA K (2011) Kinetics of copper ions sorption onto activated carbon, carbon nanotubes and carbonencapsulated magnetic nanoparticles. Coll. Surf. A: Physicochem. Eng. Aspects 377 402-408.

DENIZLI A, CIHANGIR N, TUZMEN N and ALSANCAK G (2005) Removal of chlorophenols from aquatic systems using the dried and dead fungus Pleurotus sajor caju. Bioresour. Technol. 96 59-62.

DLAMINI DS, MISHRA AK and MAMBA BB (2012a) Kinetic and equilibrium studies of the removal of $\mathrm{Pb}$ (II) from aqueous solutions 
using $\mathrm{Na}_{2} \mathrm{SO}_{4}$-EVA/Cloisite $20 \mathrm{~A}$ composite. Mater. Chem. Phys. 133 369-375.

DLAMINI DS, MISHRA AK and MAMBA BB (2012b) Adsorption behavior of ethylene vinyl acetate and polycaprolactone-bentonite composites for $\mathrm{Pb}(\mathrm{II})$ uptake. J. Inorg. Organomet. Polym. Mater. 22 342-351.

DLAMINI DS, MISHRA AK and MAMBA BB (2012c) Morphological, transport and adsorption properties of ethylene vinyl acetatepolyurethane/bentonite clay composites. J. Appl. Polym. Sci. 124 4978-4985.

DOULIA D, LEODOPOULOS C, GIMOUHOPOULOS K and RIGAS F (2009) Adsorption of humic acid on acid-activated Greek Bentonite. J. Coll. Interf. Sci. 340 131-141.

DUTTA S, PARSONS SA, BHATTACHARJEE C, BANDHYOPADHYAY S and DATTA S (2010) Development of an artificial neural network model for adsorption and photocatalysis of reactive dye on $\mathrm{TiO}_{2}$ surface. Exp. Syst. Appl. 37 8634-8638.

ERRAIS E, DUPLAY J, DARRAGI F, M'RABET I, AUBERT A, HUBER F and MORVAN G (2011) Efficient anionic dye adsorption on natural untreated clay: Kinetic study and thermodynamic parameters. Desalination 275 74-81.

FAN J, ZHANG J, ZHANG C, REN L and SHI Q (2011) Adsorption of 2, 4, 6-trichlorophenol from aqueous solution onto activated carbon derived from loosestrife. Desalination 267 139-146.

HAMEED BH, TAN IAW and AHMAD AL (2008) Adsorption isotherm, kinetic modeling and mechanism of 2, 4, 6-trichlorophenol on coconut husk-based activated carbon. Chem. Eng. J. 144 235-244.

HOEK EMV, GHOSH AK, HUANG X, LIONG M and ZINK JI (2011) Physical-chemical properties, separation performance, and fouling resistance of mixed-matrix ultrafiltration membranes. Desalination 283 89-99.

KARA H, AYYILDIZ FH and TOPKAFA M (2008) Use of aminoprophyl silica-immobilized humic acid for $\mathrm{Cu}(\mathrm{II})$ ions removal from aqueous solution by using a continuously monitored solid phase extraction technique in a column arrangement. Coll. Surf. A: Physicochem. Eng. Aspects 312 62v72.

KUMAR NS, WOO H-S and MIN K (2012) Equilibrium and kinetic studies on biosorption of 2, 4, 6-trichlorophenol from aqueous solutions by Acacia leucocephala bark. Coll. Surf. B: Biointerf. 94 125-132.

LI L, LIU F, JING X, LING P and LI A (2011) Displacement mechanism of binary competitive adsorption for aqueous divalent metal ions onto a novel IDA-chelating resin: Isotherm and kinetic modelling. Water Res. 45 1177-1188.

MAHVI AH, MALEKI A and ESLAMI A (2004) Potential of rice husk and rice husk ash for phenol removal in aqueous system. Am. J. Appl. Sci. 1 321-326.

MOTSA MM, THWALA JM, MSAGATI TAM and MAMBA BB (2011) The potential of melt-mixed polypropylene-zeolite blends in the removal of heavy metals from aqueous media. Phys. Chem. Earth 36 1178-1188.
MTHOMBO TS, MISHRA AK, MISHRA SB and MAMBA BB (2011) The adsorption behavior of $\mathrm{Cu}(\mathrm{II}), \mathrm{Pb}(\mathrm{II})$, and $\mathrm{Co}(\mathrm{II})$ of ethylene vinyl acetate-clinoptilolite nanocomposites. J. Appl. Polym. Sci. 121 3414-3424.

PEI Z, SHAN X, LIU T, XIE Y, WEN B, ZHANG S and KHAN SU (2007) Effect of lead on the sorption of 2, 4, 6-trichlorophenol on soil and peat. Environ. Pollut. 147 764-770.

PUYOL D, MOHEDANO AF, RODRIGUEZ1 JJ and SANZ JL (2011) Effect of 2, 4, 6-trichlorophenol on the microbial activity of adapted anaerobic granular sludge bioaugmented with Desulfitobacterium strains. New Biotechnol. 29 79-89.

SEN TK and GOMEZ D (2011) Adsorption of zinc (Zn(II)) from aqueous solution on natural Bentonite. Desalination 267 286-294.

SHIN K-Y, HONG J-Y and JANG J (2010) Heavy metal ion adsorption behavior in nitrogen-doped magnetic carbon nanoparticles: Isotherms and kinetic study. J. Hazardous Mater. 190 36-44.

SHUKLA A, ZHANG YH, DUBEY P, MARGRAVE JL and SHUKLA SS (2002) The role of sawdust in the removal of unwanted materials from water. J. Hazardous Mater. B95 137-152.

SÖLENER M, TUNALI S, ÖZCAN AS and GEDIKBEY AT (2008) Adsorption characteristics of $\mathrm{Pb}^{2+}$ ions onto the clay/poly (methoxyethyl) acrylamide (PMEA) composite from aqueous solutions. Desalination 223 308-322.

SUBRAMANI A, HUANG X and HOEK EMV (2009) Direct observation of bacterial deposition onto clean and organic-fouled polyamide membranes. J. Coll. Interf. Sci. 336 13-20.

SZOPA J, WRÓBEL-KWIATKOWSKA M, KULMA A, ZUK M, SKÓRKOWSKA-TELICHOWSKA K, DYMIŃSKA L, MĄCZKA M, HANUZA J, ZEBROWSKI J and PREISNER M (2009) Chemical composition and molecular structure of fibers from transgenic flax producing polyhydroxybutyrate, and mechanical properties and platelet aggregation of composite materials containing these fibers. Compos. Sci. Technol. 69 2438-2446.

TAN IAW, AHMAD AL and HAMEED BH (2009) Adsorption isotherms, kinetics, thermodynamics and desorption studies of 2, 4, 6-trichlorophenol on oil palm empty fruit bunch-based activated carbon. J. Hazardous Mater. 164 473-482

TURANA NG, MESCIB B and OZGONENEL O (2011) The use of artificial neural networks (ANN) for modeling of adsorption of $\mathrm{Cu}$ (II) from industrial leachate by pumice. Chem. Eng. J. 171 1091-1097.

TOFIGHY MA and MOHAMMADI T (2011) Adsorption of divalent heavy metal ions from water using carbon nanotube sheets. $J$. Hazardous Mater. 185 140-147.

WANG XS, LU ZP, MIAO HH, HE W and SHEN HL (2011) Kinetics of $\mathrm{Pb}$ (II) adsorption on black carbon derived from wheat residue. Chem. Eng. J. 166 986-993.

YETILMEZSOY K and DEMIREL S (2008) Artificial neural network (ANN) approach for modeling of $\mathrm{Pb}$ (II) adsorption from aqueous solution by Antep pistachio (Pistacia Vera L.) shells. J. Hazardous Mater. 153 1288-1300.

ZAGHOUANE-BOUDIAF H and BOUTAHALA M (2011) Adsorption of 2, 4, 5-trichlorophenol by organo-montmorillonites from aqueous solutions: Kinetics and equilibrium studies. Chem. Eng. J. 170 120-126.

\section{APPENDIX}

Supplemental information:

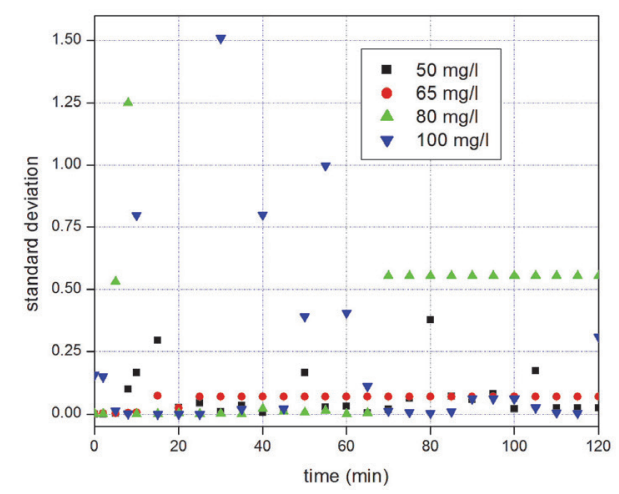

Figure $\mathrm{S1}$

Agreement between real and simulated adsorption efficiency for adsorption of TCP from water by table salt treatedOdorata.

http://dx.doi.org/10.4314/wsa.v40i2.19

Available on website http://www.wrc.org.za

ISSN 0378-4738 (Print) = Water SA Vol. 40 No. 2 April 2014

ISSN 1816-7950 (On-line) = Water SA Vol. 40 No. 2 April 2014 
http://dx.doi.org/10.4314/wsa.v40i2.19 Available on website http://www.wrc.org.za

ISSN 0378-4738 (Print) = Water SA Vol. 40 No. 2 April 2014 ISSN 1816-7950 (On-line) = Water SA Vol. 40 No. 2 April 2014 